\title{
Is there a doctor present?
}

Helle Collatz Christensen ${ }^{1}$ Stig Nikolaj Blomberg ${ }^{1}$, Ole Mazur Hendriksen ${ }^{2}$, Freddy Lippert ${ }^{1}$

${ }^{1}$ Emergency Medical Services Copenhagen, University of Copenhagen, Denmark

${ }^{2}$ Emergency Medical Services Zealand, Denmark

\section{PURPOSE OF THE STUDY}

Since 1 of January 2016 an electronic patient chart has been used to monitor the treatment of Cardiac Arrest in the whole of Denmark. The transition from paperforms to medical charts have been scrutinized and all medical charts have been evaluated to reestablish the Danish Cardiac Register. In this process we have found local differences, that could describe if we always need to have 'a doctor present?' at a Out of Hospital Cardiac Arrest (OHCA).

\section{METHODS}

Through a three year period OHCA been monitored in the electronic patient chart. We took all cardiac arrest patients in to very different regions in Denmark - one without doctors and one with. We compared the results of these two regions on incidence, sex, age, proportion of patient with ROSC, patients who were treated until hospital, where there was a doctor present or how many patients where they called a doctor at the Emergency Medical Dispatch Centre.

Return of spontanius Cirkulation uppon arrival to hospital per 100,000 inhabitants

\begin{tabular}{|l|r|r|r|}
\hline Numbers and incidence & 2016 & 2017 & \multicolumn{1}{c|}{2018} \\
\hline Denmark, $\mathrm{n}$ & 5171 & 5501 & 5382 \\
\hline Denmark, incidence & 91 & 96 & 93 \\
\hline Zealand, $\mathrm{n}$ & 997 & 1100 & 1066 \\
\hline Zealand, incidence & 120 & 132 & 128 \\
\hline Copenhagen, $\mathrm{n}$ & 1457 & 1537 & 1460 \\
\hline Copenhagen, incidence & 81 & 85 & 80 \\
\hline
\end{tabular}

Table 1: Number and incidence of cardiac arrest per 100,000 inhabitants

\section{RESULTS:}

In the three year period we found that there were a total of 4,499 and respectively 3,456 OHCA in Copenhagen and Zealand. This corresponds to a total incidence of 83 patients/100.000 inhabitants and 138 in Zealand. Comparing the two did not show any differences, when it comes to age, sex or ROSC; but more were treated with a cardiac arrest until hospital in Zealand (13\% as to $7 \%$ ). There were less doctors present to touch the patient (28\% in Zealand and 97 $\%$ in Copenhagen) and there for they rang (36\% in Zealand and $3 \%$ in Copenhagen)

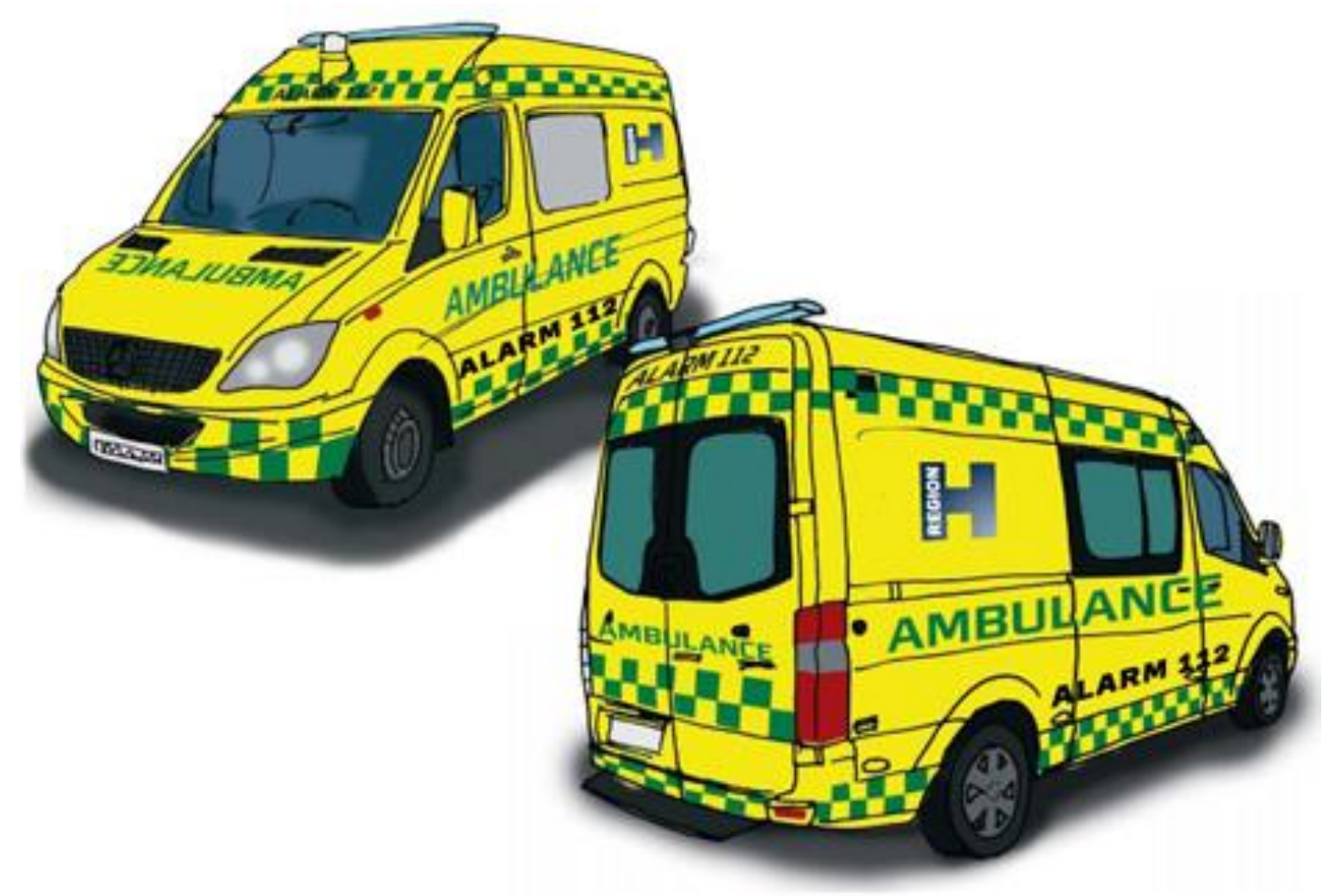

\section{CONCLUSION:}

There doesn't always need to be a doctor present, when treating cardiac arrest. In a subgroup of patients there may, but most cardiac arrest people survive the treatment of the regular ambulance personal. 